\title{
Synthesis of LY2784544
}

Key words

LY2784544

Janus kinase inhibitors

vanadium catalysis

aminomethylation

$\mathrm{N}$-arylation

SYNFACTH
A<smiles>Cc1cc2c(CN3CCOCC3)cc(Cl)nn2c1Cc1ccc(Cl)cc1F</smiles>

H<smiles>CC(N)=Nc1ccc(Cl)nn1</smiles>

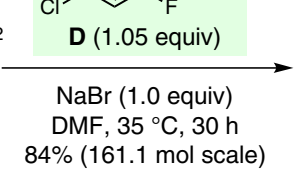

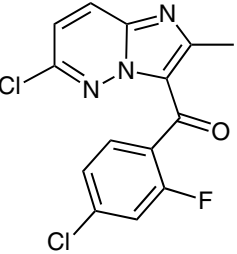

E<smiles>Cc1nc2c(CN3CCOCC3)cc(Cl)nn2c1C(=O)c1ccc(Cl)cc1F</smiles>

G

mp $146^{\circ} \mathrm{C}$

$\mathrm{mp} 143^{\circ} \mathrm{C}$

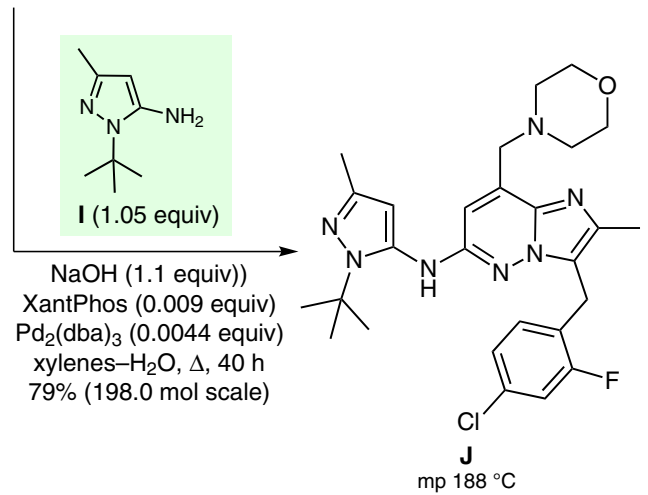<smiles>Cc1cc(Nc2cc(CN3CCOCC3)c3nc(C)c(Cc4ccc(Cl)cc4F)n3n2)[nH]n1</smiles>

Significance: LY2784544 is a Janus kinase 2 (JAK2) inhibitor that is under development for the treatment of myeloproliferative neoplasms. The synthesis depicted delivered $>100 \mathrm{~kg}$ of the target molecule and features a new aminomethylation reaction $(\mathbf{E} \rightarrow \mathbf{G})$ involving $N$-methylmorpholine $\mathrm{N}$-oxide and vanadium catalysis.
Comment: The authors speculate that the aminomethylation reaction of $\mathbf{E}$ involves a primary radical derived from $\mathrm{N}$-methylmorpholine. An alternative ionic mechanism based on an iminium salt is unlikely since $N$-methylenemorpholinium chloride reacts preferentially at the methyl group in $\mathbf{E}$ (Mannich-type reaction). 